\title{
Charles Martin Hall Relative Shares Pieces of Metallurgical History
}

\section{Lynne Robinson}

With chemicals and equipment he fabricated himself or borrowed from his college chemistry professor, Charles Martin Hall changed the world in an Ohio woodshed in 1886. His journey to discover and commercialize the electrolytic process for refining aluminum is the stuff of legend and a testament to how the power of a great idea can overcome limitations in tools, technology, and experience. "Charles Martin Hall fulfilled his life long dream and contributed a nearly unmatched contribution by any other individual patent," said Gary Tarcy, who discussed Hall's legacy in his presentation at the Aluminum Plenary Session marking the 125 th anniversary of the Hall-Héroult process at the TMS 2011 Annual Meeting on February 28.

Providing a connection to Hall- the person behind the process - at the aluminum plenary was the participation of a special guest invited by Tarcy: Emily Phillips, Hall's great-great niece. Tarcy had met Phillips at the dedication of a historical site commemorating Hall and Frank Fanning Jewett, the chemistry professor who inspired and supported Hall's early discoveries, at Oberlin College, Ohio, in 2004. When Phillips came across information online about the TMS Hall-Héroult 125th anniversary celebration, she contacted Tarcy with an offer to share a few key pieces from Charles Martin Hall's life and work. "Emily has some of the earliest aluminum pieces from Hall's invention," said Tarcy. "I thought the plenary session attendees would be interested in seeing some of the oldest aluminum metal in the world."

Describing herself as a "family custodian" of Hall's legacy, Phillips said her interest in Hall's work was sparked in high school when her grandmother showed her samples from his early experiments that had been passed down through the family. Since that time, Phillips has actively collected information and experiences related to Charles Martin Hall (Figure 1), and her quest has forged connections with the families of many of the people who helped to shape Hall's life and science.

"One of the most interesting aspects of my curiosity about Charles Martin Hall is the people I have been privileged to meet," said Phillips. "Since the story of his life and discovery is not widely known, it's been fun to uncover bits and pieces here and there.' Phillips' research has enabled her to strike up acquaintances with the family of Alfred Hunt, who invested

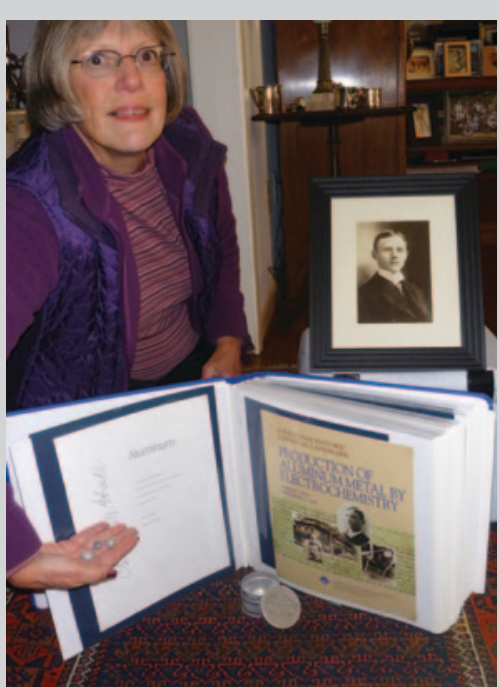

Figure 1. Emily Phillips displays the scrapbook that captures much of her research on Charles Martin Hall. The scrapbook is sitting on an Oriental rug owned by Hall, and the aluminum container in the foreground was made by the Pittsburgh Reduction Company. Phillips is also holding samples of aluminum from Hall's early experiments which have been passed down through her family. in Hall's technology to establish the Pittsburgh Reduction Company, the predecessor of Alcoa. She has also lunched in Paris with the grandson of Paul Héroult, who simultaneously and independently developed the electrolysis process and is credited as a co-inventor. She has corresponded with the daughter of Homer Johnson, a close friend of Hall's and executor of his estate, and has become a familiar face at the Mudd Library at Oberlin and with historians at Alcoa. When visiting the Hall homestead in Ohio, she made a point of climbing the stairs to the cupola "where Charles Martin Hall as a young experimenter almost burned down the house." Phillips credits Norman C. Craig, professor emeritus of chemistry at Oberlin, as her mentor in trying to uncover these and other small, but interesting, details of Hall's discovery and the impact of his work.

Phillips has presented her collection and stories on more than a few occasions, and was pleased to be a part of the TMS 2011 commemoration of Hall's discovery. "The fact that we are now celebrating a manufacturing process, which has been improved, but is still basically the same 125 years after its discovery, is very significant," she said.

Despite her dedication to filling the gaps in the historical accounts of Hall's life, Phillips said one significant mystery remains unsolved - the location of the Perkin Medal, considered the highest honor given in the United States chemical industry, which Hall received in 1911. "I have made inquiries among family members and to Alcoa and Oberlin-no one seems to know where his medal is," she said. "Perhaps some day, it will turn up!"

Lynne Robinson is a news and feature writer for TMS. 